\title{
Speech Chronemics - A Hidden Dimension of Speech. Theoretical Background, Measurement and Clinical Validity
}

\author{
H.-P.Krüger \\ Department of Psychology, University of Würzburg, FRG
}

\section{Summary}

The term "speech chronemics" is introduced to characterize a research strategy which extracts from the physical qualities of the speech signal only the pattern of ons ("speaking") and offs ("pausing"). The research in this field can be structured into the methodological dimension "unit of time", "number of speakers", and "quality of the prosodic measures". It is shown that a researcher's actual decision for one method largely determines the outcome of his study. Then, with the Logoport a new portable measurement device is presented. It enables the researcher to study speaking behavior over long periods of time (up to 24 hours) in the normal environment of his subjects. Two experiments are reported. The first shows the validity of articulation pauses for variations in the physiological state of the organism. The second study proves a new betablocking agent to have sociotropic effects: in a long-term trial socially high-strung subjects showed an improved interaction behavior (compared to placebo and socially easy-going persons) in their everyday life. Finally, the need for a comprehensive theoretical foundation and for standardization of measurement situations and methods is emphasized.

\section{The Role of Speech Chronemics in Science}

Speech is an extraordinarily telltale (Siegman. 1987) communication channel burdened with verbal and nonverbal messages. It attracts scientists with the most heterogeneous aims and methods. To foster clarity about what has been done, a variety of issues and findings must be structured into a methodological framework. The chronemic dimension of speech primarily means that all aspects of content are excluded from consideration. Therefore, chronemics can be contrasted with psycholinguistics (see Hörmann, 1981 and 1986; Herrmann, 1985, and for an excellent overview $O^{\prime}$ Connell and Kowal, 1983; O'Connell, 1988) and must be seen as a part of nonverbal communication. These nonverbal features of speech can be investigated by "phenomenal methods", as did

Pharmacopsychiat. 22(1989) 5-12 (Supplement)

(c) Georg Thieme VerlagStuttgart · New York

\section{„Speech chronemics“ - eine verborgene Dimen- sion der Sprache. Theoretischer Hintergrund, Meßbarkeit und klinische Validität}

Der Begriff „speech chronemics“ wird eingeführt, um eine Forschungsrichtung zu charakterisieren, die aus den physikalischen Qualitäten des Sprachsignals lediglich das Muster von „an“ (,Sprechen“) und „aus“ (,Pausieren") herauszieht. Die Forschungen zu diesen on-off Mustern lassen sich in die methodischen Dimensionen ,zeitliche Einheit", „Zahl der Sprecher" und „Art der prosodischen Maße" gliedern. Es wird gezeigt, daß die Entscheidung eines Untersuchers für eine bestimmte Methodik das Ergebnis seiner Untersuchung nicht unerheblich vorausbestimmt. Es wird dann mit dem Logoport ein neues tragbares Meßinstrument vorgestellt, das es erlaubt, das Sprechverhalten von probanden bis zu 24 Stunden lang in deren normaler Umgebung aufzuzeichnen. Es werden zwei Experimente beschrieben. Im ersten wird gezeigt, daß die Messung von Artikulationspausen valide den psychophysiologischen Aktivierungsstatus abbilden kann. In der zweiten Studie wird die soziotrope Wirksamkeit einer neuen betablockierenden Substanz aufgezeigt: in einer Langzeitstudie verbesserte sich das Interaktionsverhalten von Probanden, die sich sozial schwer tun, im Vergleich zu Plazebo und zum Verhalten von Personen ohne solche Schwierigkeiten. Schließlich wird mit Blick auf neue Studien die Wichtigkeit einer überlegten theoretischen Einbettung und einer Standardisierung von situativen und methodischen Merkmalen betont.
Moses (1954), by hearer ratings and evaluations (psychiatric applications may be found in Mahl, 1956, and Mahl and Schulze, 1964), or by instrumental methods based on the physical features of the speech signal.

IN principle, the physical qualities of frequency, spectrum (subjectively,pitch and timbre), and intensity (subjectively, loudness) can be evaluated. In the psychiatric environment, the spectral qualitites have been used in the diagnosis of emotional states (Williams and Stefens, 1972, 1981 ; Scherer, 1981), depression (Hargreaves, Starkweather and Blacker, 1965), and schizophrenia (Tolkmitt, Helfrich, Standke and Scherer, 1982), and in the evaluation of therapy (for an overview see Scherer, 1979, 1982a). These spectral parameters have opened a promising new approach to these areas. The signal energy (psychologically, loudness of speech) is easy to hear but difficult to measure precisely. As a consequence, it has not been evaluated extensively. Ostwald (1961, summarized in 1973) found changes during treatment 
of schizophrenics; Siegman (1988) showed loudness to be a useful parameter in psychosomatic studies with type A persons.

Further abstraction from both physical qualities reveals a hidden dimension of speech: a time structure or time pattern, represented in the on-off sequence of speech. It started with Chapple's Interaction Chronograph (1939, 1948/49, Chapple and Donald, 1946), which measured the time sequence of behavioral "acts". Verzeano and Finesinger (1949) developed an automatic system for on-off detection; it was later refined by Hardgreaves and Martin (1982). The psychopathological and psychotherapeutic implications of the temporal dimensions were mentioned by Chapple, Chapple, Wood, Miklowitz, Kline and Saunders (1960), and then extensively discussed by Matarazzo (1973), Matarazzo, Wiens and Saslow (1965), and Matarazzo, Wiens, Matararazzo and Saslow (1968), Who adapted Chapple's methodology for their purposes. In Germany, speech-pause parameters have been used in psychotherapeutic (Brähler and Overbeck, 1981) and depression (Klos, 1984; Ellgring, 1976) research.

The famous psycholinguistic researcher Goldman-Eisler also started with the evaluation of time sequences of conversational behavior (1951, summarized in 1968). The most remarkable advance was pioneered by Jaffe and Feldstein (1970) with the construction and use of the Automatic Vocal Transactional System (Avta; Cassotta, Feldstein and Jaffe, 1964). The extensive use of this apparatus in the "Baltimore School" with Feldstein and Siegman is well documented and integrated in a synopsis of nonverbal communication (Siegman and Feldstein, 1985, 1987). Their success (e.g., in psychopharmacology, see Feldstein and Welkowitz, 1987; Jaffe, Dahlberg, Luria, Breskin, Chorosh and Lorick, 1972) stimulated clinical applications such as those of the other "Baltimore Group" (Stitzer, Griffiths, Bigelow and Liebson, 1981; Stitzer, McCaul, Bigelow and Liebson, 1984). Developments outside of psychology (but nevertheless very important for our investigations) can be noted in the technical sciences (e.g., telephone communication): Norwine and Murphy (1938); Brady (1965, 1968); Gruber (1982); Schramm(1987).

All these approaches eliminate all qualities of the speech signal except time itself. They use an apparatus which by means of the speech energy yields the time pattern of verbal behavior. This is ordinarily accomplished by use of an analog threshold which transforms the flow of energy into onoff patterns. Thus, the only psychological determinant under observation is time. To emphasize this unidimensional approach, we here propose the name speech chronemics. Feldstein and Welkowitz (1987) used the title "chronography of conversation". In my opinion, the term "conversation" suggests a content-oriented approach, whereas this research is concerned only with time. The term "chronemics" was introduced by Poyatos (1972), who suggested it "as an area of study that would deal with our conceptualizations and handling of time as a biopsychological and cultural element" (p. 61).

\section{The Methodology of Speech Chronemics}

Given an apparatus like the Logoport described below, which measures this time pattern of speech, an actual investigation involves three methodological decisions.
- Time level: What is the shortest event to be

measured?

- Scope of observation: Is the emphasis on individual or on group behavior?

- Observational parameters: Is the study interested in static or dynamic features of time?

\section{Time Level of Observation}

Figure 1 indicates that on-off patterns of speech are realized at at least four different time levels. At the "Macro-Level", a whole day is divided into periods of talks ("conversations") and pauses in between. For detecting these macro-events a resolution speed of measurement (where the apparatus inquires as to speaking or not speaking) of about 1 minute would be quite enough. Questions to be answered at this level include; How many talks does a person have throughout the day? How long are they? How long are the pauses between conversations? These questions are covered by the term intertalk variance.

"Zooming" into one single conversation reveals a new on-off pattern: the sequence of utterances and pauses (or "turns"). Given 2 seconds as a lower limit for utterance duration, this "Upper Meso-Level" is characterized by a resolution speed of about 1 second (1 cycle per second). A slight increase in resolution speed up to $5 \mathrm{cps}(200 \mathrm{~ms})$ breaks up one utterance into the smaller unit of "phonemic clauses" (Trager and Smith, 1951; Trager, 1958) or "vocalizations", which are content-oriented aggregations of phonemes with a special phrasing contour. Well-known categories of pauses at this level are the juncture and hesitation pauses, lasting between 200 and $500 \mathrm{~ms}$ (Boomer and Dittmann, 1962). The events of this "Lower Meso-Level" and of the "Upper MesoLevel" cover the intratalk variance.

Another zoom into these vocalizations opens up the new microcosmos of articulation. At this "MicroLevel", the phenomenologically continuous speech flow turns out to be a very discontinuous course of physical energy. The complicated mechanics of speech production are very timeconsuming, yielding a fast on-off pattern. For example, the simple word "top" is pronounced with a pause of about $80 \mathrm{~ms}$ before the plosive " $p$ ".

Up to now the psychological impact of this articulatory variance has not been studied extensively. One of the reasons is the contention of "Goldman-Eisler" (1968) that below $250 \mathrm{~ms}$ only pure speech mechanics occurs. Therefore, "breaks in phonation of less than $0.25 \mathrm{sec}$ were not considered as discontinuities" (p. 12). Together with practical problems of measurement, her opinion has disconraged research into this time level up to the present.

Table 1 summarizes the time levels and events with their limits of resolution speed in milliseconds and cycles per second. In addition, medians and interquartile ranges from our own research are given for most of the parameters.

It is immediately evident that the physically determined resolution speed of the apparatus has in fact been the deciding factor with regard to the psychological units. Technical shortcomings have hitherto limited research to the meso- 


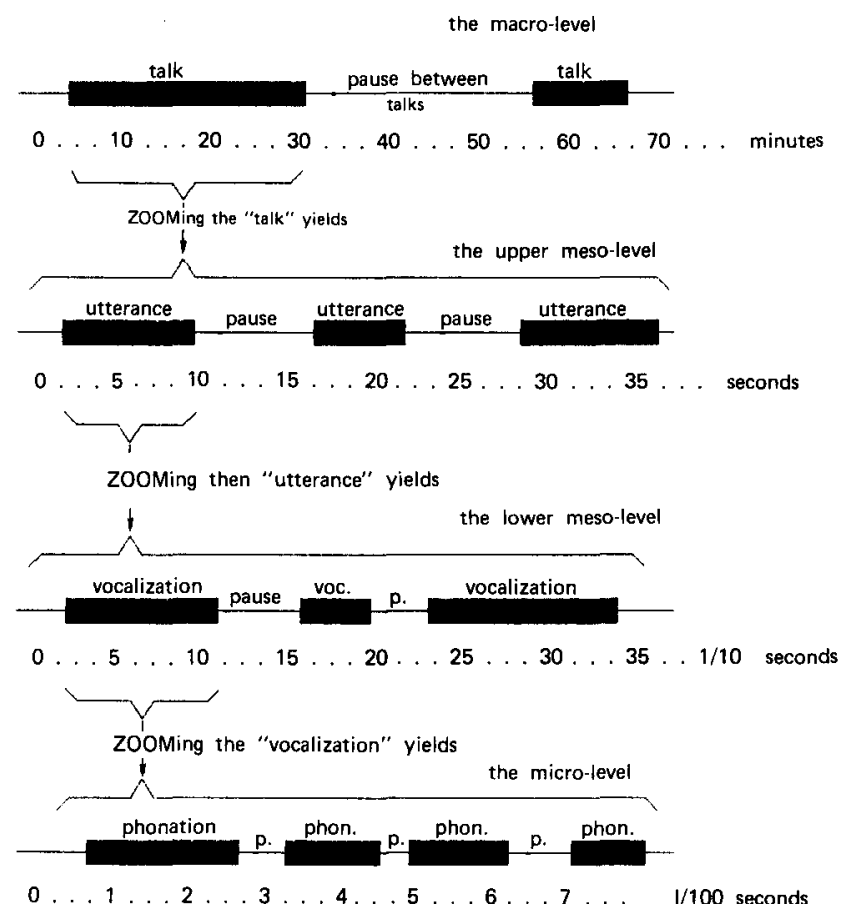

Fig. 1 The four different time levels of speech chronemics.

level, thereby excluding the microcosmos of articulation. The problems with the macro-level are also instrumental ones: the field evaluation of speech behavior requires a portable intelligent apparatus with on-line evaluation capability.

\section{Speaking vs. Communicating - The Num- ber of Participants}

Two aspects of speaking must be considered here: it is one of the most refined motoric capabilities of the human organism (along with eye movements) and it is a highly developed mode of communication. To separate these two basic features, two experimental procedures have been used. One is to give the subject different speaking tasks, such as reading a text or counting (e.g., Szabadi, Bradshaw and Bresson, 1976) forward or backward. This approach belongs to the canon of psychometric assessment techniques of psychological functions.

The other procedure is the recording of real interactions between two (e.g., patients, patient and therapist) or more (e.g., group discussion) persons. In this case, the basic axiom of gestalt psychology holds that the whole (das Ganze) is quite different from the qualities of its parts (Lewin, 1951, p. $189 f$., requires a separate observer for the group itself). This fact necessitates a twofold consideration of communication: both the behavior of the partners and the behavior of the group (dyad or social unit) are important.

The former approach is a component of personality research. Are there a variety of stable interaction behaviors? Do these behaviors correlate with other personality dimensions? Are they affected by mood, etc.? The latter approach entails questions that require a simultaneous look at all the speakers. The measurable events are rate and duration of switching pauses, simultaneous talking, mutual silence, interruption, back channeling or breaks (e.g., "mmh"), etc. These parameters not only characterize the persons involved but give interesting descriptions of the nature of the dialog itself. In honor of Cattell this approach may appropriately be termed "syntality", the "personality of the interaction" (Krüger, 1986a).

The most obvious feature distinguishing these dimensions methodologically is the number of participants. The levels of this dimension are given by single speech (mono$\log$ ), dyadic and group speech (multilog), where dyadic is a special but important case of group speech.

\section{Observational Parameters}

Some descriptive parameters derived from onoff runs take time sequence into account; some do not. Rhythm, for example, is essentially time-structured sequences. Only recently it has become a topic of research (Davis, 1982; Krüger, 1986b). In contrast, measures such as average duration of utterances/pauses or the respective variances, though indeed measures of time, are not measures of time sequences. The course of time cannot be described by statistics that sum over time. For example, the trumpet part in Beethoven's 5th symphony cannot be analyzed into the mean

Table 1 Resolution speed for different time levels and median values for events at these levels.

\begin{tabular}{|c|c|c|c|c|c|c|}
\hline Level and event & Range in ms & CPS & 1st Quartile & Median & 3rd Quartile & unit \\
\hline $\begin{array}{l}\text { upper meso-level } \\
\text { turns, utterances } \\
\text { pauses between turns }\end{array}$ & $1000 \ldots 25000$ & $1 \ldots 1 / 25$ & $\begin{array}{l}1676 \\
1208\end{array}$ & $\begin{array}{l}3096 \\
2628\end{array}$ & $\begin{array}{l}5784 \\
6700\end{array}$ & $\begin{array}{l}\mathrm{ms} \\
\mathrm{ms}\end{array}$ \\
\hline $\begin{array}{l}\text { micro-level } \\
\text { phonations } \\
\text { articulation pauses }\end{array}$ & $40 \ldots 200$ & $25 \ldots 5$ & $\begin{array}{l}56 \\
64\end{array}$ & $\begin{array}{l}80 \\
88\end{array}$ & $\begin{array}{l}120 \\
120\end{array}$ & $\begin{array}{l}\mathrm{ms} \\
\mathrm{ms}\end{array}$ \\
\hline
\end{tabular}




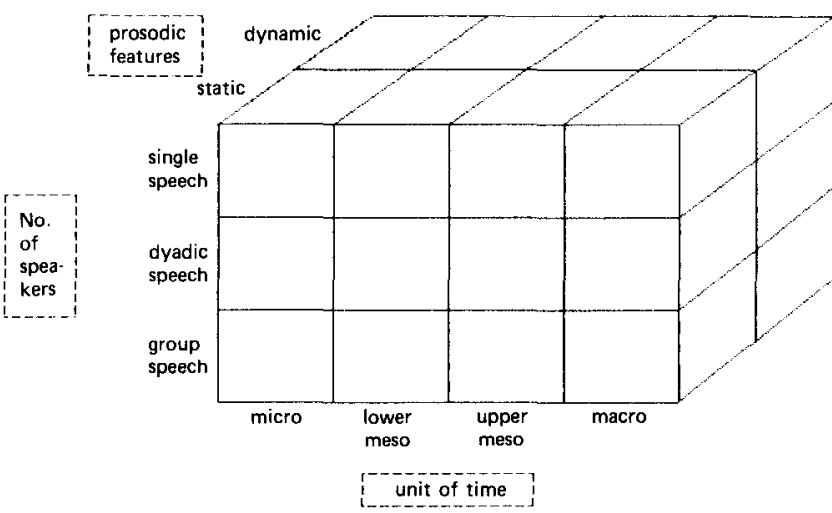

Fig. 2 The methodological cube of speech chronemics.

and variance of its playing time! A third dimension is therefore invoked: the bipolarity of static versus dynamic descriptive parameters.

\section{The Methodological Cube}

Each empirical datum in speech chronemics can be classified according to three dimensions, as illustrated in Figure 2: concern with personality or syntality; time level; descriptively static or dynamic. the overwhelming majority of studies reported in the literature can be classified as concerned with personality at the meso-level, and descriptively static. Only a few studies have dealt with syntality (in particular the "rhythm studies" mentioned above). Little is known about the macro-level and micro-level.

\section{Reliability and Validity}

The classifications shown in Figure 2 are important methodologically. All the dimensions are defined objectively and recorded in physical terms, and are physical measures of time. Psychological and psychiatric research can accordingly address two basic questions.

1. What parameters can be derived from the methodological considerations and how precise and reliable are the measurements?

2. What is their validity, what do they indicate (symptomatology)?

Up to now, there has been no comprehensive overview of these questions in the literature. And for two reasons: on the one hand, very few studies exist on the macro- and micro-levels, on the other hand, the existing literature on the meso-level is based on empirical results that have been derived from quite heterogeneous methods, from typically uncontrolled situations, and from subjects or patients who have not been adequately described. Appropriate reanalyses of all these data would be well-nigh impossible.

Preliminary indications as to the validity of the various cells in the methodological cube can be derived from our own research, carried out with the help of the Logoport equipment described below. In general, then, we have found that:

- Research on articulation variance (microlevel) is an efficient tool in the measurement of psychomotorics. This variance turns out to be very sensitive to motoric retardation.

- The meso-level reveals arousal and emotional states of speakers. The "voice of depression", of anxiety, of Type A persons is best described by parameters at this level. Additionally, if variation in speech is predicted from cognitive performance, this level is the most promising one for measuring the effects.

- The macro-level is the proper domain of social interaction. Variation in social motivation and in the social environment are reflected in the intertalk variance, and in the number, duration, and "contour" (time shape) of conversations throughout an entire day.

In order to satisfy both theoretical and practical standards, research in speech chronemics must be carried out more systematically in keeping with the distinctions of the methodological cube. There must also be a standardization of the measurement techniques for both instrumental and situational features. One way that we have found to standardize speech chronemics has been through a new measurement device called the Logoport. This apparatus will be described and its capabilities demonstrated for the two research levels most neglected to date.

\section{The Logoport}

The principles of design follow directly from methodological considerations. The existence of various time levels requires a variable resolution speed (and/or an efficient bottom-up algorithm from "fast" data to "slow" events, as proposed by Krüger, Rausche and Vollrath, 1989). Further, the situational requirement that field observation be extended over long periods of time necessitates a portable device. In order to integrate speech behavior within the general topic of social arousal, an ECG recording is also incorporated.

\section{Apparatus \\ Technical Design}

The Logoport (Krüger, 1987; Krüger and Rimkus, 1989) consists of a microprocessor, a 512 kilobyte CMOS memory, a $40 \mathrm{MHz}$ quartz clock, a recording unit for speech energy, and a unit for ECG recording. Signal evaluation, analog-digital conversion, interfacing with the environment (programming, data reading), a continuous check on all functions, and registration of failures are controlled by a microprocessor. Power supply for about 24 hours in the recording mode is provided by rechargeable batteries that are easily changeable by the subject as needed. Recorded data can be stored in memory (standby mode) for more than a month before being read out. All these components are contained in a small box $(164 \times 108 \times 30 \mathrm{~mm}$, weight $800 \mathrm{~g})$ worn by the subject on a shoulder strap. Figure 3 shows the Logoport with the electrodes for the ECG and the microphone taped at the subject's throat. 


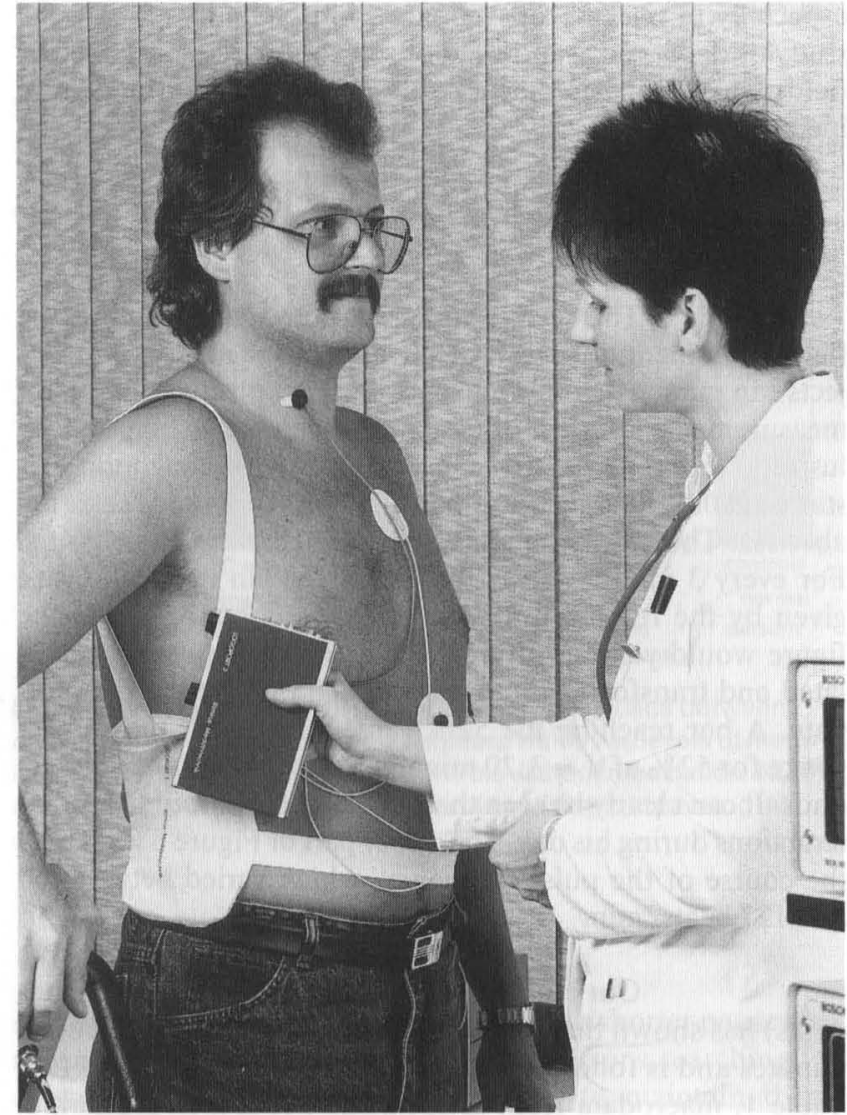

Fig. 3 The Logoport with the electrodes for the ECG and the microphone taped to the subject's throat. The device is worn on a shoulderstrap.

\section{Speech Recording}

A condensor microphone is taped to the subject's throat and connected to the main device. There, the current of the microphone is amplified, high-pass filtered, and rectified. Then the signal is compared every millisecond with an adjustable threshold and an on-off pattern is produced. This pattern is evaluated every $8 \mathrm{~ms}$ as to whether more than 2 units of $1 \mathrm{~ms}$ have been "on". If so, the total pattern is classified as "speaking"; otherwise is "pause". The parameters 8 (the resolution speed) and 2 (actually a digital filter) can be changed by the user. Information about the pattern is efficiently stored in memory in bytes of variable length.

\section{ECG Evaluation}

Before $\mathrm{A} / \mathrm{D}$ conversion, a very new evaluation system filters and transforms the ECG signal from the chest electrodes so that a very stable detection of the RS complex is possible even in critical recording situations (particularly those involving movement artefacts). The interbeat interval is calculated (precision $1 \mathrm{~ms}$ ) and stored. In order to determine a possible loss of the signal within each minute, the precise time of day is written into memory, thus allowing a reliable reconstruction of the measurement.

\section{Procedure}

At the beginning of an actual measurement, the Logoport is connected to a PC. By means of a computer program, all system thresholds and variables are adjusted for each subject. The clock is programmed to start the Logoport at a given time, thus allowing a perfect synchronization between two or more Logoports. Then, the subject is free to spend his or her normal day. Or, in the case of laboratory research, the experiment may begin. At the end of the measurement, the subject removes the device and returns it to the experimenter. Then the data are read out and calculated by a computer program.

\section{Research at the Micro-Level- Articulation Pauses}

In fluent speech small pauses can be found which are caused by the so-called plosives "p", "t", "k". Motoric production of these requires about $80 \mathrm{~ms}$. During this time no energy is measurable. Libermann (1979) has shown that these pauses are important conditions for understanding speech. In the geniculate body of the inner ear neuronal elements have been found, some of which are excited only by pauses of $50 \mathrm{~ms}$, and others which only react to pauses longer than 120 ms (Aitkin and Dunlop, 1968; Spreng, 1980). These findings indicate the significance of this articulation pause. It seems to be the smallest unit of pause production and detection by the ear. The importance of such a physiological unit for the measurement of variations in the psychomotoric process should be clear.

It is fairly complicated to detect these pauses in fluent speech. Therefore, we synchronized two Logoports. Logoport 2 was connected to the microphone at the subject's throat. Logoport 1 received as input an on-off signal as to whether a light was on or off (see upper part of Figure 4). When the experimenter switched the light on, the subject was to start to produce an "a" sound. After a variable time (1-4 seconds) the experimenter switched the light off. As fast as possible the subject had to stop the "a" and to produce a "ta". The lower part of Figure 4 shows the Logoport measurements. From these data, a reaction time and an articulation pause can be calculed.

We found that the articulation pauses were independent of reaction time, indicating that different mechanisms are responsible for the regulation of these two motoric responses. Moreover, our subjects were unable to vary these articulation pauses. In fact, it is possible to lengthen them (trivially) but not to shorten them. At this point, we introduced caffeine as a stimulant. Two healthy young volunteers took $200 \mathrm{mg}$ caffeine and were subjected to the "a-ta" test before, and 10, 20, 40,80, and 160 minutes after, receiving the caffeine.

The results are given in Figure 5. Caffeine induces a roughly $30 \mathrm{~ms}$ (or $25 \%$ ) shortening of the articulation pause. The effect diminishes within two hours and covaries very well with the blood level of the drug.

These results convincingly prove the validity of speech motorics as an indicator of basic variations in the physiological state of the organism. Many applications are possible, 

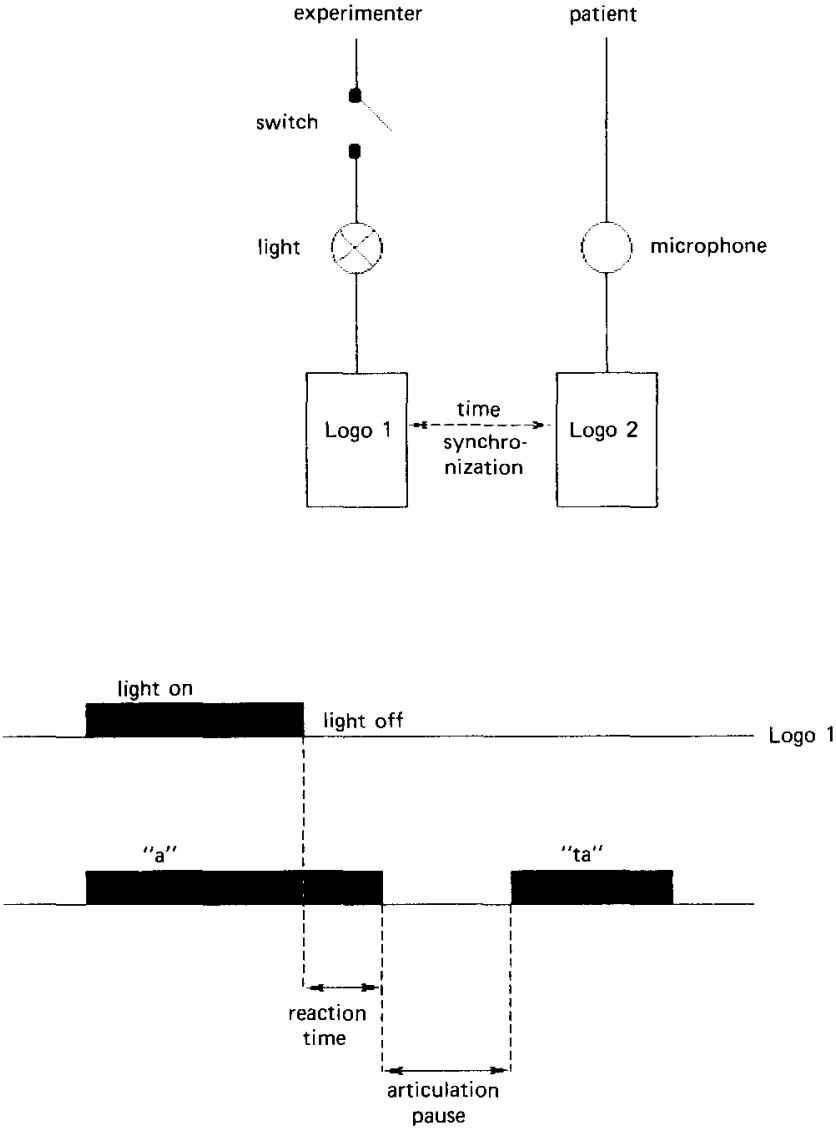

Fig. 4 The "a-ta" design (see text for explanation).

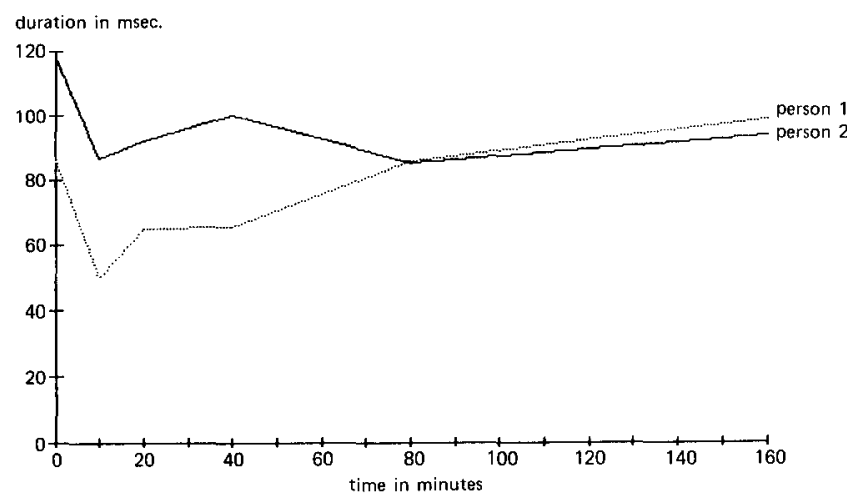

Fig. 5 Variations in articulation pauses induced by $200 \mathrm{mg}$ caffeine p.o. Time since intake at the abscissa. especially in pharmacopsychology, in psychiatry (e.g., in the study of depression, and even of schizophrenia), and in other fields where "physiological readiness" is an important variable.

\section{Research on the Macro-Level- Sociotropic Effects}

The second topic neglected in research is the field assessment of speech behavior. With the Logoport, subjects can pursue their normal activities and produce long-term measurements of their interactional behavior. Figure 6 illustrates the result of such a measurement. The Logoport was started at $08: 30$ and was stopped at 17:30, as can be seen on the abscissa. Therefore, the total measurement time was 9 hours. For every 3 minutes and 20 seconds ("d" in the figure, size given by the resolution of the screen, a zooming inside the figure would yield a different " $d$ ") the $0-1$ data were cumulated and transformed into percent values, given at the ordinate. A bar reaching the $52 \%$ value means that the subject spoke for $52 \%$ of $d=3: 20$ minutes, or for 104 out of $200 \mathrm{sec}$ onds. It can clearly be seen that this subject hadfour longer interactions during his day. The upper part of Figure 6 visualizes the course of the pulse frequency, which varied between 60 and 127 beats/min.

Our research with normal people (mainly students) has shown that the average conversation lasts about 20 minutes and is followed by a pause of about 45 minutes (see Table 1, macrodata from Heidenfelder, 1985). In a pharmacopsychological study we proved that a new betablocking agent (Ciba Geigy CGP $361 \mathrm{~A}$ ) has effects on interactional behavior, as had been hypothesized based on findings of animal studies (Jaekel, 1987). Following the paradigm of symptomatic volunteers, we selected 36 healthy young subjects ( 18 women and 18 men) who described themselves as "socially easy-going" or "socially hard-driving", respectively. The former reported having no problems in social contacts, searching for social support in difficult situations, etc. Despite their interest in interactions, the hard-driving persons reported experiencing stress and anxiety in communicating with other persons.

The subjects were randomly and double-blind assigned to the medication levels: placebo, 10 , and $20 \mathrm{mg}$. The same doses were given over 4 days. The results of the field study are depicted in Figure 7. Compared to easy-going persons and to controls from our other studies (right side of the figure), the hard-driving persons under placebo are character-

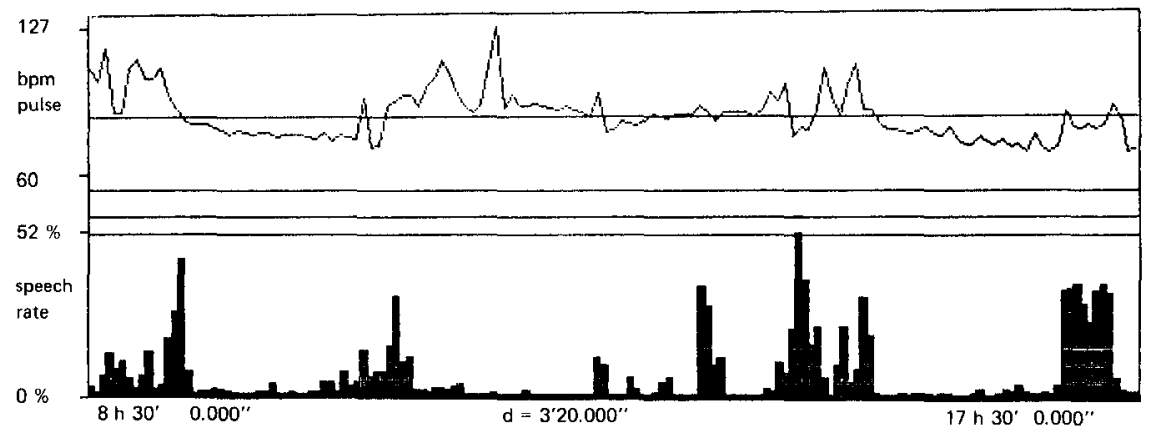

Fig. 6 A Logoport measurement: ECG in the upper part, speech activity in the lower part. 


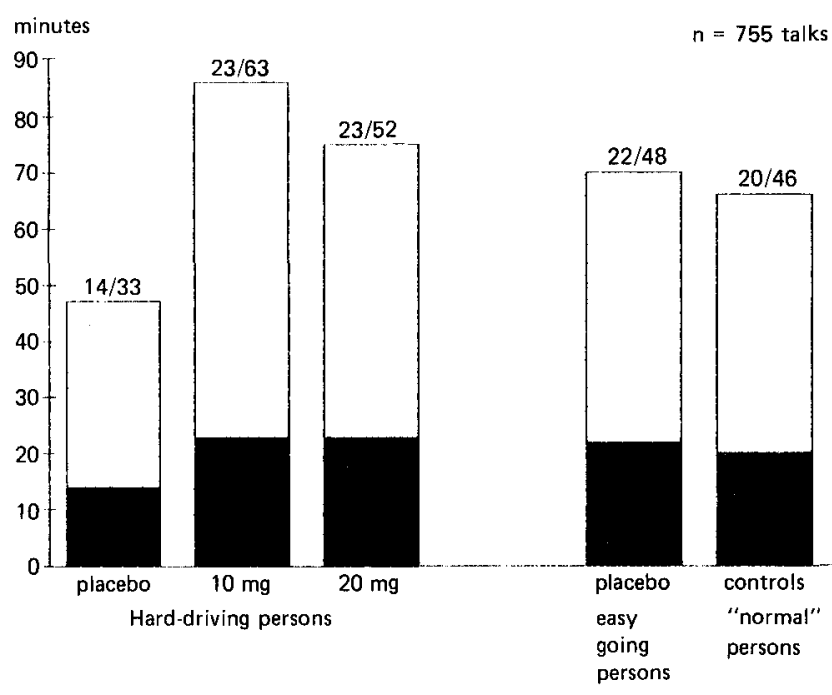

Fig. 7 Average duration of conversations and pauses between conversations for hard-driving volunteers with three levels of medication, easy-going persons, and controls without medication. Numbers at the top of the bars give means of speaking and pausing in minutes.

ized by more but shorter conversations with shorter pauses between them. They can be described as persons searching for contact, initiating contacts, but unable to maintain them. Therefore, the outcome of their interactions is unsatisfactory, after a short pause, a new attempt is started. The drug seems to be able to normalize this interaction behavior (see Krüger, 1985; Kohnen and Krüger, 1986).

\section{Conclusions}

From its earliest beginnings, research on speech chronemics has been found to be very efficient in the psychiatric environment. Existing psychiatric knowledge about the validity of speech behavior could be transformed into objective measurements and new diagnostic approaches could be inaugurated. Current methods are characterized by a refinement of measurement methods. Faster digitalization speeds, portable apparatus, and more elaborate calculation methods all require a new methodological framework and a new theoretical conceptualization. One must recognize the fact that research on speech is yielding information in at least four areas: psychomotorics, emotions and arousal, cognitive functioning, and social interaction. This multiple information requires precise and rational examination in order to discern which psychiatric disorders are characterized by which speech feature. The "general effect on speech" conceptualized in early research has a given way to a systems-oriented approach in which effects on the subsystems of speech can be predicted from biological and psychiatric models. One must also recognize that different methodological strategies lead to different results. Hence, the need for a standardization of situations and methods is an urgent one. The suggestions presented here constitute an efficient behavior-oriented approach.

\section{References}

Aitkin, L. M., C. W. Dunlop: Interplay of excitation and inhibition in the cat medial geniculate body. J. Neurophysiol. 31 (1968) 44-61

Boomer, D.S., A. T. Dittmann: Hesitation pauses and juncture pauses in speech. Lang. Speech 5(1962) 215-220

Brady, P. T.: A technique for investigating on-off patterns of speech. Bell Syst. Tech.J.44 (1965) $1-22$

Brady, P. T.: A statistical analysis of on-off patterns in 16 conversations. Bell Syst. Tech. J. 47 (1968) 73-91

Brähler, E., A. Overbeck: Die Erfassung der Interaktion in familientherapeutischen Sitzungen durch die automatische Analyse des Sprechverhaltens. Med. Psychol. 7 (1981) 79-94

Brähler, E., A. Overbeck, D. Braun, H. Junker: Was kann die automatische Sprachanalyse des Sprech-Pausen-Verhaltens (on-off pattern) vonArzt und Patient für die Beurteilung von Psychotherapien leisten? Z. Psychosom. Med. Psychoanal. 20 (1974) 148 163

Brähler, E., H. Zenz: Apparative Analyse des Sprechverhaltens in der Psychotherapie. Z. Psychosom. Med. Psychoanal. 20 (1974) $328-$ 336

Cassotta, L., S. Feldstein, J. Jaffe: AVTA: A device for automatic vocal transaction analysis. J. Anal. Behav. 7 (1964) 99- 104

Chapple, E. D.: Quantitative analysis of the interaction of individuals. Prof. Nat. Acad. Sci. USA 25 (1939) 58-67

Chapple, E. D.: The Interaction. Chronograph: its evolution and present application. Personnel 25 (1948/49) 295-307

Chapple, E. D.: Movement and sound: The musical language of body rhythms in interaction. In: Davis, Martha (ed.) Interaction Rhythms. Human Sciences Press, New York (1982) 31 - 52

Chapple, E. D., M. F. Chapple, L. A. Wood, A. Miklowitz, N. S. Kline, $C$. Saunders: Interaction-Chronograph method for analysis of differences between schizophrenics and controls. Arch. Gen. Psychiatry 3 (1960) $160-167$

Chapple, E. D., G. Donald: A method of evaluationg supervisory personnel. Harv. Business Rev. 24 (1946) 197-214

Davis, M. (ed.): Interaction Rhytms. Human Sciences Press, New York 1982

Ellgring, $J$. H.: Kommunikatives Verhalten im Verlauf depressiver Erkrankungen. In: Tack, W. H. (ed.) Bericht über den 30. Kongreß der DGfPs. Hogrefe, Göttingen (1976) 190-192

Feldstein, S. J., A. Welkowitz: A chronography of conversation: In defense of an objective approach. In: Siegman, A. W., S. Feldstein (eds.) Nonverbal Behavior and Communication. Lawrence Erlbaum, Hillsdale (1987) 435-500

Goldman-Eisler, F.: The measurement of sequences in conversational behavior. Br. J. Psychol. 42 (1951) 355-362

Goldman-Eisler, F.: Psycholinguistics. Experiments in Spontaneous speech. Academic Press, New York 1968

Gruber, J. G.: A comparison of measured and calculated speech-temporal parameters relevant to speech activity detection. IEEE Trans. Commun. COM-30 (1982) 728-738

Hargreaves, W. A., J. A. Starkweather: Collection of temporal data with the Duration Tabulator. J. Exp. Anal. Behav. 2 (1959) 179 183

Hargreaves, W. A., J. A. Starkweather, K. H. Blacker: Voice quality in depression. J. Abnorm. Soc. Psychol. 70 (1965) 218-220

Hargrove, D. S., T. A. Martin: Development of a microcomputer system for verbal interaction analysis. Behav. Res. Methods Instrum. 14 (1982) 236-239

Heidenfelder, K.: Objektive Registrierung des Sprechverhaltens. Allgemeinpsychologische und differentielle Sensibilitäten des Logoport. Thesis, Würzburg 1985

Herrmann, T.: Allgemeine Sprachpsychologie. Urban \& Schwarzenberg, München 1985

Hörmann, H.: Einführung in die Psycholinguistik. Wissenschaftliche Buchgesellschaft, Wiesbaden 1981

Hörmann, H.: Meaning and context: An Introduction to the Psychology of Language. Plenum, New York 1986

Jaekel, J.: Der Einfluß ausgewählter Psychopharmaka auf Kommunikationsabläufe bei Rhesusaffen. In: Keupp, W. (ed.) Biologische Psychiatrie. Springer, Berlin (1986) 29-38 
Jaffe, J., C. C. Dahlberg, J. Luria, S. Breskin, J. Chorosh, E. Lrick: Speech rhythms in patient monologues: The influence of LSD and dextroamphetamine. Biol. Psychiatry 4 (1972) 243-246

Jaffe, J., S. Feldstein: Rhythms of dialogue. Academic Press, New York 1970

Klos, T.: Sprechgeschwindigkeit und Sprechpuusen von Depressiven. In: Hauntzinger, M., R. Straub (eds.) Psychologische Aspekte depressiver Störungen. Roderer, Regensburg 1984

Kohnen, R., H.-P. Krüger: Drug effects on human social behavior: Changes in talking activities induced by a betablocking agent.Pharmacopsychiatry 19 (1986) $186-187$

Krüger, H.-P.: Was ist Sprechen? Objektive Registrierung des Sprechverhaltens im Alltag mit dem Logoport. In: Czogalik, D, W. Ehlers, R. Teufel (eds.) Perspektiven der Psychotherapieforschung. Hochschulverlag, Freiburg (1985) 349-361

Krüger, H.-P.: Nonverbal characteristics of verbal behavior. A biological approach to personality and syntality. In: Proceedings of the Conference on Current Trends in Nonverbal Communication. Arkansas 1986a

Krüger, H.-P.:Territoriality in speech behavior. In: Proceedings of the 5 th International Conference on Human Ethiology, Tutzing 1986b

Krüger, $H .-P$.: The Logoport - a new measurement device for the study of verbal behavior in the open field. In: Proceedings of the 58th Annual Meeting of the Eastern Psychological Association, Arlington 1987

Krüger, H.-P., A. Rausche, M. Vollrath:Time levels in speech behavior and their detection. In preparation, 1989

Krüger, H.-P., U. Rimkus: The Logoport. A new device to measure speech activity. In preparation. 1989

Lewin, K.: Feldtheorie in den Sozialwissenschaften. Huber, Bern $1951 / 1963$

Liebermann, A. M.: An ethological approach to language through the study of speech perception. In: Cranach, M.v., K. Foppa, W. Lepenies, D. Ploog (eds.) Human Ethology. Cambridge University Press, Cambridge (1979) 682-704

Linden, M., N. Hoffmann: Die Bedeutung sequentieller Beobachtung von Verbalverhalten für die Diagnose und Therapie depressiven Verhaltens. In: Tack, W. H. (ed.) Bericht über den 30 . Kongreß der DGfPs in Regensburg. Hogrefe, Göttingen 1977

$M a h l, G . F$. : Disturbances in silences in the patients' speech in psychotherapy. J. Abnorm. Soc. Psychol. 53 (1956) $1-15$

Mahl, G. F., G. Schulze: Psychological research in the extralinguistic area. In: Sebeock, T. A., A. S. Hayes, M. C. Bateson (eds.) Approaches to Semiotics. Mouton, The Hague (1964) $51-124$

Matarazzo, J. D.: A speech interaction system. In: Kiesler, D. J. (ed.) The process of Psychotherapy. Aldine, Chicago (1973) 138-146

Matarazzo, J. D., A. N. Wiens, R. G. Matarazzo, G. Saslow: Speech and silence behavior in clinical psychotherapy and its laboratory correlates. In: Shlien, J. M., H. F. Hunt, J. D. Matarazzo (eds.) Research in Psychotherapy. American Psychological Association, Washington D.C. (1968) 347-394

Matarazzo, J. D., A. N. Wiens, G. Saslow: Studies in interview speech behavior. In: Krasner, L., L. P. Ullmann (eds.) Research in Behavior Modification. Holt, Rinehart \& Winston. New York (1965) $179-212$

Moses, P. J.: The Voice of Neurosis. Grune \& Stratton, New York 1954

Norwine, A. C., O. J. Murphy: Characteristic time intervals in telephonic conversation. Beil Syst. Tech. J. 17 (1938) 281 - 291

$O$ 'Connell, D. C.: Critical Essays on Language Use and Psychology. Springer, New York 1988

O'Connell, D. C., S. Kowal: Pausology: In: Sedelow, W., S. Sedelow (eds.) Computers in Language Research (Vol. 2). De Gruyter, Berlin (1983) $221-301$

Ostwald, P. F.: The sounds of emotional disturbance. Arch. Gen. Psychiatry 5 (1961) $587-592$

Ostwald, P. F.: The Semiotics of Human Sound. Mouton, The Hague 1973

Poyatos, F.: The communication system of the speaker-actor and his culture. A preliminary investigation. Linguistics 83 (1972) 64-86
Scherer, $K . R$. : Nonlinguistic vocal indicators of emotion and psychopathology. In: Izard, C. E. (ed.) Emotions in Personality and Psychopathology. Plenum, New York (1979) 493-529

Scherer, K. R.:Speech and emotional states. In: Darby, J. (ed.) Speech Evaluation in Psychiatry. Grune \& Stratton, New York (1981) 189-220@LITERATURI = Scherer, $K$. R.: Methods of research on vocal communication. Paradigms and paramotors. ln: Scherer, K. R., P. Ekman (eds.) Handbook of Methods in Nonverbal Behavior Research. Cambridge University Press, Cambridge (1982a) $136-198$

Scherer, K. R. (ed.):Vokale Kommunikation. Beltz, Weinheim 1982b

Schramm, H.: Untersuchungen an Sprachdetektoren für digitale Sprachinterpolationsverfahren. Thesis, Erlangen 1987

Siegman, $A$. W.: Expressive correlates of affective states and traits. In: Siegman, A. W., S. Feldstein (eds.) Multichannel Integrations of Nonverbal Behavior. Lawrence Erlbaum, Hillsdale (1985) 37-68

Siegman, $A$. $W$.: the telltale voice: Nonverbal messages of verbal communication. In: Nonverbal Behavior and Communication, ed. by A. W. Siegman, S. Feldstein. Lawrence Erlbaum, Hillsdale (1987) $351-434$

Siegman, A. W.: Typ A und danach: Die Bedeutung von Feindseligkeit, Neurotizismus und Sprechstil für koronare Herzerkrankungen. Z. Klin. Pschyol. Psychother. (1988) in press

Siegman, A. W., S. Feldstein (eds.): Multichannel Integrations of Nonverbal Behavior. Lawrence Erlbaum, Hillsdale 1985

Siegman, A. W., S. Feldstein (eds.): Nonverbal Behavior and Communication. Lawrence Erlbaum, Hillsdale 1987

Spreng, M.: Physiological background of speech decoding processes in the brain. In: La Percezione del Linguaggio. Presso l'Accademia della Crusca, Firenze (1980) 9-44

Stitzer, M. L., R. R. Griffiths, G. E. Bigelow, I. A. Liebson: Human social conversation: Effects of ethanol, secobarbital, and chlorpromazine. Pharmacol. Biochem. Behav. 13 (1981) 353-360

Stitzer, M. L., M. E. McCaul, G. E. Bigelow, I. A. Liebson: Hydromorphone effects on human conversational speech. Psychopharmacology (Berlin) 84 (1984) 402-404

Street, R. L., J. N. Capella (eds.): Sequence and Pattern in Communicative Behavior. Edward Arnold, London 1985

Szabadi, E., C. M. Bradshaw, J. H. O. Bresson: Elongation of pause time in speech: A simple, objective measure of motor retardation in depression. Br. J. Psychiatry 129 (1976) 592-597

Tolkmitt, F. J., H. Helfrich, R. Standke, K. R. Scherer: vokale Indikatoren des Therapieverlaufs bei depressiven und schizophrenen Patienten. In: Scherer, K. R. (ed.) Vokale Kommunikation. Beltz, Weinheim (1982) 364-378

Trager, G. L.: Paralanguage: A first approximation. Stud. Linguistics $13(1958) 1-12$

Trager, G. L., H. L. Smith: An Outline of English Structure. Norman, Oklahoma 1951

Verzeano, M., J. Finesinger: An automatic analyzer for the study of speech in interaction and in free association. Science 110 (1949) $45-46$

Williams, C. E., K. N. Stevens: Emotions and speech: Some acoustical correlates. Acoust. Soc. Am. 52 (1972) 1238-1250

Williams, C. E., K. N. Stevens: Vocal correlates of emotional states. In: Darby, J. (ed.) Speech Evaluation in Psychiatry. Grune \& Stratton, New York 1981

\section{Prof. Dr. H.-P. Krüger}

Psychologisches Institut

der Universität Würzburg

Röntgenring 11

D-8700 Würzburg

FRG 